\title{
Prognostic Value of Metabolic Parameters in Patients with Synchronous Colorectal Cancer Liver Metastasis Following Curative-Intent Colorectal and Hepatic Surgery
}

\author{
Hyo Sang Lee ${ }^{1}$, Hye Ok Kim ${ }^{1}$, Yong Sang Hong ${ }^{2}$, Tae Won $\mathrm{Kim}^{2}$, Jin Cheon $\mathrm{Kim}^{3}$, Chang Sik Yu , and Jae Seung Kim ${ }^{1}$ \\ ${ }^{I}$ Department of Nuclear Medicine, Asan Medical Center, University of Ulsan College of Medicine, Seoul, Korea; ${ }^{2}$ Department of \\ Oncology, Asan Medical Center, University of Ulsan College of Medicine, Seoul, Korea; and ${ }^{3}$ Department of Surgery, Asan Medical \\ Center, University of Ulsan College of Medicine, Seoul, Korea
}

\begin{abstract}
Synchronous colorectal cancer liver metastasis (SCLM) remains a clinical challenge, largely because of the limited availability of tools that use reliable prognostic indicators to guide treatment. This study assessed the prognostic ability of preoperative ${ }^{18} \mathrm{~F}-\mathrm{FDG}$ PET/ CT in patients with SCLM who had undergone curative-intent colorectal and liver surgery. Methods: All included patients had undergone simultaneous colorectal and hepatic surgery to treat SCLM. Cox regression for survival analysis was undertaken using clinicopathologic variables and metabolic parameters (metabolic tumor volume [MTV], total lesion glycolysis [TLG], and peak standardized uptake value [SUV $\left.V_{\text {peak }}\right]$ ) as covariates, with tumor recurrence and death used as endpoints. Results: One hundred twenty patients ( 82 men, 38 women; mean age \pm SD, $59.9 \pm 10.1 \mathrm{y}$ ) met the inclusion and exclusion criteria. Univariate analysis showed that MTV, TLG, and the size of hepatic metastases were significant indicators of both recurrence-free survival and overall survival, whereas those of primary colorectal tumors were not. Multivariate analysis revealed that the SUV $V_{\text {peak }}$ of primary tumors and hepatic metastases remained significant after adjusting for other clinicopathologic variables, whereas the MTV and TLG of hepatic metastases became insignificant after adjusting for differences in tumor size. The combination of a high SUV peak of hepatic metastases and a low SUV peak of primary tumors was related to poor prognosis under the multivariate model. Conclusion: In patients with SCLM who underwent curative-intent colorectal and liver surgery, metabolic parameters of hepatic metastases possess prognostic significance whereas those of primary colorectal tumors do not. For hepatic metastases, the $S V_{\text {peak }}$ is an independent prognostic factor, whereas MTV and TLG are surrogate measures of tumor size. Reduced recurrencefree survival rates are associated with higher SUV $_{\text {peak }}$ for hepatic

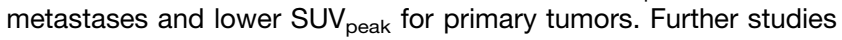
are needed to elucidate the underlying mechanisms.
\end{abstract}

Key Words: synchronous colorectal liver metastasis; ${ }^{18}$ F-FDG PET/CT; prognosis; prognostic score; prognostic model

J Nucl Med 2014; 55:582-589

DOI: 10.2967/jnumed.113.128629

Received Jul. 2, 2013; revision accepted Nov. 1, 2013.

For correspondence or reprints contact: Jae Seung Kim, Department of Nuclear Medicine, Asan Medical Center, University of Ulsan College of Medicine, 88 Olympic-ro 43-gil, Songpa-gu, Seoul 138-736, Korea. E-mail: jaeskim@amc.seoul.kr

Published online Feb. 17, 2014.

COPYRIGHT (c) 2014 by the Society of Nuclear Medicine and Molecular Imaging, Inc.
C encer (CRC) accounts for much of the global morbidity and mortality associated with cancer, especially in developed countries. The liver is the single most common site of distant metastasis; up to $50 \%$ of CRC patients develop liver metastasis during the course of the disease, and $20 \%-25 \%$ of patients with newly diagnosed CRC present with synchronous liver metastasis at the time of initial diagnosis (1-3).

Hepatic metastasectomy is the standard of care to treat liver metastasis when curative surgery is feasible. However, the prognosis after hepatectomy is poor, with the 5- and 10-y survival rates after hepatectomy being approximately $40 \%$ and $25 \%$, respectively (4). The prognosis is even poorer for patients with synchronous hepatic metastasis (a hepatic metastasis presented at the same time of its primary colorectal tumor) than for those with metachronous hepatic metastasis (a hepatic metastasis that has developed after the resection of the primary colorectal tumor) (5-7). Several previous investigators have developed prognostic scoring systems to improve patient selection for hepatic metastasectomy and as criteria for patient stratification in clinical trials (8-10).

The unsatisfactory outcome reflects the absence of widely accepted criteria to select patients for hepatectomy (4) and the unsatisfactory and inconsistent results associated with previously developed prognostic scoring systems that use clinicopathologic variables (11). This underscores the need for a new prognostic model that uses biologic and clinicopathologic factors to guide treatment of the patients with $\operatorname{SCLM}(11,12)$.

${ }^{18} \mathrm{~F}-\mathrm{FDG}$ PET/CT uses the increased rates of glucose metabolism in tumors to characterize the biology of different cancers, with several studies having reported that high rates of ${ }^{18} \mathrm{~F}-\mathrm{FDG}$ uptake in tumors are associated with increased aggressiveness and poor survival $(13,14)$. However, only a limited number of studies have addressed the prognostic ability of ${ }^{18} \mathrm{~F}-\mathrm{FDG}$ PET/CT in patients with CRC liver metastasis (15-17). In particular, no published article has dealt exclusively with SCLM, for which the prognosis is worse than the prognosis for metachronous metastasis. The greater severity of SCLM than metachronous metastasis underscores the importance of aggressive chemotherapy and the selection of patients for whom surgery is appropriate.

This study evaluated the prognostic ability of preoperative ${ }^{18} \mathrm{~F}$ FDG PET/CT in patients with SCLM who had undergone curativeintent colorectal and liver surgery. Standardized uptake values (SUVs) and the volumetric parameters, such as metabolic tumor 
volume (MTV) and total lesion glycolysis (TLG), were analyzed as potential prognostic factors.

\section{MATERIALS AND METHODS}

\section{Inclusion and Exclusion Criteria}

Patients diagnosed as having colorectal adenocarcinoma with synchronous liver metastasis and who had undergone curative-intent (i.e., without macroscopic residual tumor) simultaneous colorectal and hepatic surgery between January 2006 and June 2011 in our institution and who did not receive neoadjuvant treatment were retrospectively identified. Exclusion criteria included combined radiofrequency ablation or ethanol ablation for treatment of liver metastases, distant metastases other than liver metastases, overt double primary malignancy, hereditary CRC, loss of follow-up immediately after surgery (within $3 \mathrm{mo}$ ), and absence of data generated by preoperative PET/CT. This retrospective cohort study was approved by the institutional review board (2013-0403), and the requirement to obtain informed consent was waived.

\section{Clinicopathologic and Survival Data}

Clinicopathologic data considered to be potentially relevant to prognosis were collected from the patients' medical records. Data included age at surgery, sex, TNM stage, the preoperative serum carcinoembryonic antigen level, the number and size of hepatic metastases and their locations (lobes), the size of primary colorectal tumors, the resection margin positivity of hepatic metastases, and differentiation grade. The sizes of hepatic metastases and primary colorectal tumors were defined as the longest diameters of the tumors. For patients with multiple hepatic metastases, the diameter of the largest tumor was used. Clinical risk scores developed by Fong et al. for predicting survival after hepatic resection for metastatic CRC were also calculated (8).

Recurrence-free survival (RFS) was defined as the interval from the day of surgery to the date of cross-sectional imaging (CT, PET/CT, or MR imaging) when tumor recurrence was first identified. All tumor recurrences were confirmed by pathology or at clinical follow-up. Overall survival (OS) was defined as the interval from surgery to death.

\section{Acquisition and Analysis of ${ }^{18} \mathrm{~F}-\mathrm{FDG}$ PET Data}

Patients underwent ${ }^{18} \mathrm{~F}$-FDG PET/CT on 1 of the 3 scanners operated in our hospital (Discovery ST [GE Healthcare] and Biograph 16 and Biograph 40 [Siemens Medical Solutions]). All patients fasted for at least $6 \mathrm{~h}$ before the ${ }^{18} \mathrm{~F}$-FDG PET/CT scan. After the venous blood glucose level was confirmed to be below $150 \mathrm{mg} / \mathrm{dL},{ }^{18} \mathrm{~F}-\mathrm{FDG}(5.2 \mathrm{MBq} / \mathrm{kg}$ body weight) was injected intravenously, and PET/CT scanning commenced $50 \mathrm{~min}$ later. Images were reconstructed using a 3-dimensional orderedsubset expectation maximization algorithm, and CT attenuation maps were used for attenuation correction. The SUV was calculated according to the standard formula, using lean body mass as the body weight.

Issues with interscanner difference had to be addressed before semiquantitative image analysis could be performed, because the 3 scanners used in this study had different voxel sizes and reconstruction parameters and because the widely used maximum SUV $\left(\mathrm{SUV}_{\max }\right)$ is sensitive to these configurations (18). We mitigated this problem in 2 ways. First, we used peak SUV $\left(\mathrm{SUV}_{\text {peak }}\right)$ instead of $\mathrm{SUV}_{\text {max }}$. The $\mathrm{SUV}_{\text {peak }}$ was defined as the average SUV within a 1.2 -cm-diameter spheric volume of interest (VOI) positioned around the voxel of highest SUV. This voxel-averaging procedure reduces the effects of differences in voxel sizes on the resultant $\mathrm{SUV}_{\text {peak }}(19)$. Second, we normalized the tumor $\mathrm{SUV}_{\text {peak }}$ by dividing it by the mean $\mathrm{SUV}\left(\mathrm{SUV}_{\text {mean }}\right)$ within a 3$\mathrm{cm}$-sized reference VOI positioned in the normal liver parenchyma. This procedure was performed to address the problem of possible cross-calibration error among the scanners. These normalized $\mathrm{SUV}_{\text {peak }}$ $\left(\mathrm{nSUV}_{\text {peak }}\right)$ figures were used in the analysis.
The $\mathrm{nSUV}_{\text {peak }}$, MTV, and TLG of both the primary colorectal tumor and every hepatic metastasis were calculated. All PET/CT data in DICOM format were transferred to a workstation and analyzed using TrueD software (Siemens Medical Solutions). A 3-dimensional ellipsoid isocontour tool implemented in TrueD was used to draw appropriate VOIs. We applied an isocontour threshold of $50 \% \mathrm{SUV}_{\text {peak }}$ to delineate the tumor boundaries. When $50 \%$ of the $\mathrm{SUV}_{\text {peak }}$ of a hepatic metastasis was smaller than the $\mathrm{SUV}_{\text {mean }}+4 \mathrm{SDs}$ of the reference liver VOI, the $\mathrm{SUV}_{\text {mean }}+4 \mathrm{SDs}$ was used as the threshold to prevent inclusion of normal liver into the tumor VOI. MTV was defined as the volume $\left(\mathrm{cm}^{3}\right)$ within the tumor VOI. TLG was calculated as the product of MTV and $\mathrm{SUV}_{\text {mean }}$ within the VOI. The TLG was normalized by dividing it by the $\mathrm{SUV}_{\text {mean }}$ of the normal liver to produce the normalized TLG (nTLG), which was used in the analysis. In the cases of multiple hepatic metastases, MTV and nTLG values of each hepatic metastasis were added, and the sums were used in the analysis. When hepatic metastases could not be distinguished from the surrounding normal liver tissue by PET, VOIs were drawn manually at the appropriate locations with the aid of contrast-enhanced CT or MR imaging.

In addition to these individual metabolic parameters, a set of composite variables (M/P ratios) were calculated and used in the survival analysis. The $\mathrm{M} / \mathrm{P}$ ratio of $\mathrm{SUV}_{\text {peak }}$ was defined as the ratio of the $\mathrm{SUV}_{\text {peak }}$ of the hepatic metastasis to that of the primary colorectal tumor. M/P ratios of MTV and TLG were defined in the same manner.

\section{Statistical Analysis}

Survival analysis was undertaken using clinicopathologic and PET parameters as covariates and tumor recurrence and death as endpoints. The durations of RFS and OS were calculated using the Kaplan-Meier method. Univariate Cox regression analysis was performed for each potential prognostic variable. Variables with a $P$ value of less than 0.25 by univariate analysis were included in the multivariate analysis. Multivariate Cox regression was performed for selected combinations of prognostic factors to determine the independent prognostic significance of each combination. Construction of the multivariate survival models involved a 2-block design, with different entry methods used for each block. In the first block, we entered variables without entry and removal thresholds (i.e., fixed variables). In the second block, we entered the remaining variables and applied backward elimination (entry threshold, $P<0.05$; removal threshold, $P>0.1$ ). Using $\beta$-coefficients in the multivariate models as weights, we calculated prognostic scores for RFS ( $\left.\mathrm{PS}_{\mathrm{RFS}}\right)$ and $\mathrm{OS}\left(\mathrm{PS}_{\mathrm{OS}}\right)$. The deciles of $\mathrm{PS}_{\mathrm{RFS}}$ and $\mathrm{PS}_{\mathrm{OS}}$ that produced the lowest $P$ values were chosen as the optimal cutoff points for dichotomizing patients into good and poor prognostic groups. Differences in the survival rates of these 2 groups were demonstrated using Kaplan-Meier curves and the log-rank test.

The degree of correlation was shown using either the Pearson correlation coefficient $r$ or Spearman rank correlation coefficient $\rho$.

SPSS software (version 18.0; SPSS Inc.) was used for all statistical analysis.

\section{RESULTS}

\section{Patient and Tumor Characteristics}

Screening of patients identified 198 who fulfilled the inclusion criteria. Elimination from the study group of patients who met the exclusion criteria left 120 patients who were included in the analysis (Fig. 1). The 78 excluded patients (39\%) did not significantly differ from the 120 included patients in terms of the clinicopathologic characteristics listed in Table 1, except for the number of hepatic metastases and the proportion of bilobar hepatic metastases, which were significantly higher in the excluded patients $(P=0.001$ and $<0.001$, respectively), probably because the patients who underwent radiofrequency ablation tended to 


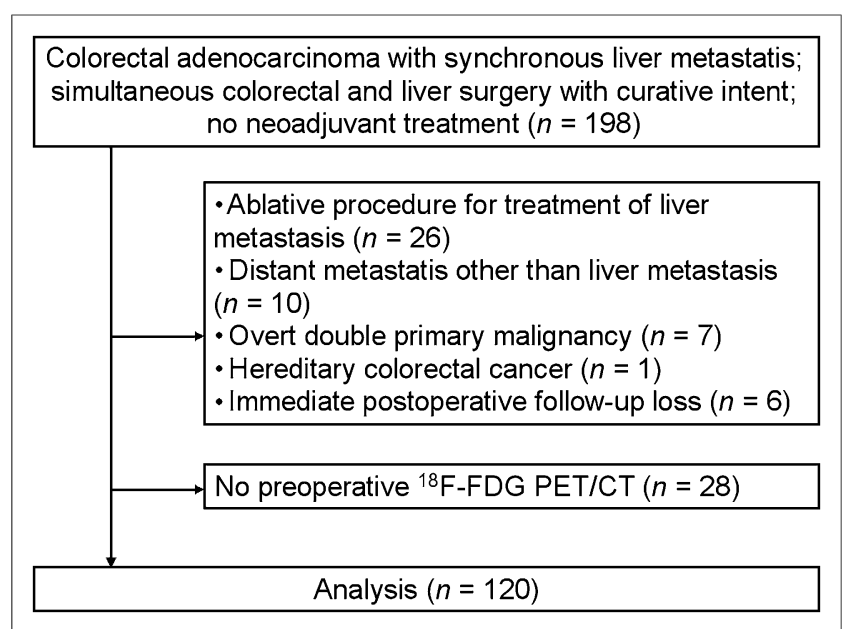

FIGURE 1. Flow diagram outlining criteria used for patient inclusion and exclusion.

possess more disseminated hepatic metastases than the surgically cured patients. Tables 1 and 2 summarize the demographics and tumor characteristics of the 120 enrolled patients. There was no early postoperative mortality (within $30 \mathrm{~d}$ of surgery). In 3 patients, both MTV and nTLG were calculated as zero because the $\mathrm{SUV}_{\max }$ of the hepatic metastases was below the threshold. The level of plasma glucose determined at the time of the ${ }^{18} \mathrm{~F}$ FDG PET/CT scan was less than $150 \mathrm{mg} / \mathrm{dL}$ in all patients (range, $72-148 \mathrm{mg} / \mathrm{dL})$.

\section{Survival Characteristics}

Among the 120 patients analyzed, 77 (64\%) experienced tumor recurrence during follow-up. The median follow-up duration of the 43 recurrence-free patients was $39.4 \mathrm{mo}$ (range, 17.0-67.3 mo). Oneyear and 17-mo RFS rates were 61\% (73/120) and 49\% (59/120), respectively. The mean RFS for all 120 patients was 30.2 mo $(95 \%$ confidence interval [CI], 25.2-35.1). Sites of tumor recurrence were liver only (44 patients, $57 \%$ ), liver and other organs (5 patients, $6 \%$ ), lung (14 patients, $18 \%$ ), the site of colorectal surgery ( 2 patients, $3 \%$ ), peritoneum ( 5 patients, $6 \%$ ), or other sites (6 patients, $7 \%$ ).

Forty patients $(33 \%)$ died during follow-up. The median followup duration of the 80 surviving patients was 43.9 mo (range, 23.0-89.0 mo). The 1-y and 23-mo OS rates were 98\% (117/120) and $88 \%(105 / 120)$, respectively. The mean OS for all 120 patients was $63.8 \mathrm{mo}(95 \% \mathrm{CI}, 57.8-69.9)$.

\section{Univariate and Multivariate Survival Analysis}

Univariate Cox regression analysis was undertaken to evaluate the prognostic potential of each variable (Tables 3 and 4). The M/P ratio of $\mathrm{SUV}_{\text {peak }}$ and the number of hepatic metastases were significantly associated with RFS $(P<0.05)$. The size, $\mathrm{nSUV}_{\text {peak }}$, MTV, and nTLG values of the hepatic metastases were of borderline significance $(0.05<P<0.10)$. Sex, $\mathrm{nSUV}_{\text {peak }}$, and MTV of the primary tumor; differentiation grade; and Fong's clinical risk score were weakly associated with RFS $(0.10<P<0.25)$.

Similar results were found for OS, with some differences. The $\mathrm{nSUV}_{\text {peak }}$, nTLG, and size of the hepatic metastases and differentiation grade were significantly associated with OS $(P<0.05)$. The MTV of hepatic metastases and the M/P ratio of $\mathrm{SUV}_{\text {peak }}$ were of borderline significance $(0.05<P<0.10)$. Age, preoperative serum carcinoembryonic antigen, and adjuvant chemotherapy were weakly associated with OS $(0.05<P<0.25)$.
Before undertaking the multivariate analysis, a correlation coefficient matrix was calculated to address the problem of multicolinearity (Supplemental Table 1; available at http://jnm. snmjournals.org). The correlation coefficients between any pairs of the size, MTV, and nTLG of hepatic metastasis were greater than 0.8 , suggesting possible complications caused by multicolinearity. On the other hand, the nSUV peak $_{\text {of hatic metastases }}$ was only weakly correlated with MTV, nTLG, or tumor size $(r<$ $0.5)$. The correlation coefficients between other potential prognostic variables were all small $(<0.4)$.

Multivariate Cox regression analysis generated 4 models for RFS (Table 5) and another 4 for OS (Table 6). First models (models 1 and 5) included nSUV peak and the size of hepatic metastases as the fixed variables. Second models (models 2 and 6) included the $\mathrm{M} / \mathrm{P}$ ratio of $S U V_{\text {peak }}$ and the size of hepatic metastases as the fixed variables. Third models (models 3 and 7) included the MTV

TABLE 1

Demographics and Clinicopathologic Features of Primary Colorectal Cancers and Liver Metastases

\begin{tabular}{|c|c|}
\hline Characteristic & $n$ or mean $\pm \mathrm{SD}$ \\
\hline Age (y) & $59.9 \pm 10.1$ (range, 35-80) \\
\hline \multicolumn{2}{|r|}{ 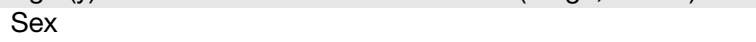 } \\
\hline Male & $82(68 \%)$ \\
\hline Female & $38(32 \%)$ \\
\hline \multicolumn{2}{|l|}{$\begin{array}{l}\text { carcinoembryonic } \\
\text { antigen }(\mathrm{ng} / \mathrm{mL})\end{array}$} \\
\hline \multicolumn{2}{|l|}{ Pathologic stage } \\
\hline \multicolumn{2}{|l|}{$\mathrm{T}$} \\
\hline T2 & $1(1 \%)$ \\
\hline T3 & $107(89 \%)$ \\
\hline T4 & $12(10 \%)$ \\
\hline \multicolumn{2}{|l|}{$\mathrm{N}$} \\
\hline NO & $29(24 \%)$ \\
\hline N1 & $47(39 \%)$ \\
\hline $\mathrm{N} 2$ & $44(37 \%)$ \\
\hline \multicolumn{2}{|l|}{ Location of primary tumor } \\
\hline Colon & $74(62 \%)$ \\
\hline Rectum & $46(38 \%)$ \\
\hline \multicolumn{2}{|l|}{ Bilobar hepatic metastasis } \\
\hline Yes & $21(17 \%)$ \\
\hline No & $99(83 \%)$ \\
\hline \multicolumn{2}{|l|}{ Hepatic resection margin } \\
\hline Positive & $13(11 \%)$ \\
\hline Negative & $107(89 \%)$ \\
\hline \multicolumn{2}{|l|}{ Differentiation grade } \\
\hline Well differentiated & $4(3 \%)$ \\
\hline Moderately differentiated & $110(92 \%)$ \\
\hline Poorly differentiated & $6(5 \%)$ \\
\hline \multicolumn{2}{|l|}{$\begin{array}{c}\text { Number of hepatic } \\
\text { metastasis }\end{array}$} \\
\hline 1 & $70(59 \%)$ \\
\hline 2 & $29(24 \%)$ \\
\hline 3 & $10(8 \%)$ \\
\hline$>3$ & $11(9 \%)$ \\
\hline Size of primary tumor (cm) & $5.5 \pm 1.8$ (range, $1.7-11.2)$ \\
\hline $\begin{array}{l}\text { Size of hepatic metastasis } \\
\quad(\mathrm{cm})\end{array}$ & $3.5 \pm 2.4$ (range, $0.4-14.0)$ \\
\hline \multicolumn{2}{|l|}{ Adjuvant chemotherapy } \\
\hline No & $4(3 \%)$ \\
\hline Yes & $116(97 \%)$ \\
\hline Total & $120(100 \%)$ \\
\hline
\end{tabular}


TABLE 2

Metabolic Features of Primary Colorectal Cancers and Liver Metastases

\section{Metabolic parameter}

SUV $V_{\text {mean }}$ of normal liver

$S U V_{\text {peak }}$ of primary tumor

nSUV $_{\text {peak }}$ of primary tumor

SUV $_{\text {peak }}$ of hepatic metastasis

nSUV $_{\text {peak }}$ of hepatic metastasis

MTV of primary tumor $\left(\mathrm{cm}^{3}\right)$

MTV of hepatic metastasis $\left(\mathrm{cm}^{3}\right)$

nTLG of primary tumor $\left(\mathrm{cm}^{3}\right)$

nTLG of hepatic metastasis $\left(\mathrm{cm}^{3}\right)$

Data in parentheses are ranges.

and the size of hepatic metastases as the fixed variables. Fourth models (models 4 and 8 ) included the nTLG and the size of hepatic metastases as the fixed variables. The remaining potential prognostic variables underwent backward stepwise elimination in each model construction.

Multivariate analysis revealed that the $\mathrm{nSUV}_{\text {peak }}$ of hepatic metastases is a prognostic factor for RFS that is independent of the size or number of hepatic metastases (Table 5, model 1). On the other hand, MTV or TLG of hepatic metastases did not remain significant when adjusted for the size of hepatic metastases (Table 5 , models 3 and 4). Although the $\mathrm{nSUV}_{\text {peak }}$ of both the primary tumors and the hepatic metastases were not significant in the univariate analysis, they became significant by multivariate analysis (Table 5, model 1). In this model, a higher $\mathrm{nSUV}_{\text {peak }}$ of the primary tumors was unexpectedly associated with better RFS. Because of this result, the $\mathrm{M} / \mathrm{P}$ ratio of $\mathrm{SUV}_{\text {peak }}$ was significantly associated with the prognosis after adjusting for other clinicopathologic variables (Table 5, model 2).

In multivariate analysis, the $\mathrm{nSUV}_{\text {peak }}$ of the hepatic metastases remained significant for OS $(P=0.013)$ despite adjustment for the sizes of hepatic metastases and the differentiation grade (Table 6, model 5). On the other hand, MTV and nTLG again became insignificant after adjusting for the sizes of hepatic metastases (Table 6 , models 7 and 8 ).

Using $\beta$ coefficients in models 2 and 5 as weights, we calculated $\mathrm{PS}_{\mathrm{RFS}}$ and $\mathrm{PS}_{\mathrm{OS}}$ as follows:

$\mathrm{PS}_{\mathrm{RFS}}=0.508 \times \mathrm{sex}+0.735 \times \mathrm{MPR}_{\mathrm{SUV}}+0.070 \times \mathrm{S}_{\mathrm{H}}+0.185 \times \mathrm{N}_{\mathrm{H}}$

$$
\begin{aligned}
\mathrm{PS}_{\mathrm{OS}}= & 0.035 \times \mathrm{A}-0.152 \times \mathrm{SUV}_{\mathrm{P}}+0.363 \times \mathrm{SUV}_{\mathrm{H}} \\
& +0.032 \times \mathrm{S}_{\mathrm{H}}+1.344 \times \mathrm{DG}
\end{aligned}
$$

TABLE 3

\begin{tabular}{|c|c|c|c|c|c|c|c|}
\hline \multirow[b]{2}{*}{ Variable } & \multirow[b]{2}{*}{$n$} & \multicolumn{3}{|c|}{ RFS } & \multicolumn{3}{|c|}{ OS } \\
\hline & & Hazard ratio & $95 \% \mathrm{Cl}$ & $P$ & Hazard ratio & $95 \% \mathrm{Cl}$ & $P$ \\
\hline Age $(y)$ & 120 & 1.009 & $0.987-1.032$ & 0.428 & 1.034 & $1.000-1.069$ & 0.052 \\
\hline \multicolumn{8}{|l|}{ Sex } \\
\hline Female & 38 & - & - & - & - & - & - \\
\hline Male & 82 & 1.462 & $0.885-2.414$ & 0.138 & 1.308 & $0.639-2.677$ & 0.462 \\
\hline Size of primary tumor $(\mathrm{cm})$ & 120 & 1.034 & $0.908-1.176$ & 0.617 & 0.982 & $0.826-1.168$ & 0.838 \\
\hline Size of hepatic metastasis $(\mathrm{cm})$ & 120 & 1.088 & $0.998-1.187$ & 0.055 & 1.131 & $1.016-1.259$ & 0.025 \\
\hline Preoperative serum carcinoembryonic antigen $(\mathrm{ng} / \mathrm{mL})$ & 120 & 1.001 & $0.999-1.003$ & 0.298 & 1.002 & $0.999-1.004$ & 0.179 \\
\hline \multicolumn{8}{|l|}{ T stage } \\
\hline T2, T3 & 108 & - & - & - & - & - & - \\
\hline T4 & 12 & 1.194 & $0.595-2.396$ & 0.617 & 1.019 & $0.361-2.876$ & 0.972 \\
\hline \multicolumn{8}{|l|}{$\mathrm{N}$ stage } \\
\hline NO & 29 & - & - & 0.822 & - & - & 0.776 \\
\hline N1 & 47 & 0.881 & $0.494-1.571$ & 0.667 & 1.281 & $0.557-2.947$ & 0.560 \\
\hline N2 & 44 & 1.031 & $0.578-1.839$ & 0.919 & 1.035 & $0.434-2.471$ & 0.937 \\
\hline \multicolumn{8}{|l|}{ Positive hepatic resection margin } \\
\hline No & 107 & - & - & - & - & - & - \\
\hline Yes & 13 & 1.315 & $0.656-2.639$ & 0.440 & 1.518 & $0.637-3.620$ & 0.346 \\
\hline No. of hepatic metastasis & 120 & 1.200 & $1.009-1.427$ & 0.039 & 1.058 & $0.858-1.304$ & 0.596 \\
\hline \multicolumn{8}{|l|}{ Bilobar hepatic metastasis } \\
\hline No & 99 & - & - & - & - & - & - \\
\hline Yes & 21 & 0.886 & $0.488-1.609$ & 0.691 & 0.735 & $0.288-1.880$ & 0.521 \\
\hline \multicolumn{8}{|l|}{ Differentiation grade } \\
\hline Well or moderately differentiated & 114 & - & - & - & - & - & - \\
\hline Poorly differentiated & 6 & 1.934 & $0.703-5.324$ & 0.202 & 5.234 & $1.803-15.196$ & 0.002 \\
\hline \multicolumn{8}{|l|}{ Location of primary tumor } \\
\hline Colon & 74 & - & - & - & - & - & - \\
\hline Rectum & 46 & 1.265 & $0.803-1.992$ & 0.310 & 0.986 & $0.524-1.857$ & 0.966 \\
\hline \multicolumn{8}{|l|}{ Adjuvant chemotherapy } \\
\hline No & 4 & - & - & - & - & - & - \\
\hline Yes & 116 & 0.585 & $0.214-1.605$ & 0.298 & 0.414 & $0.099-1.738$ & 0.228 \\
\hline Fong's clinical risk score & 120 & 1.225 & $0.891-1.683$ & 0.214 & 1.310 & $0.850-2.021$ & 0.224 \\
\hline
\end{tabular}

Univariate Cox Regression Analysis for Clinicopathologic Risk Factors Associated with Survival 
TABLE 4

Univariate Cox Regression Analysis for Metabolic Risk Factors Associated with Survival

\begin{tabular}{|c|c|c|c|c|c|c|c|}
\hline \multirow[b]{2}{*}{ Variable } & \multirow[b]{2}{*}{$n$} & \multicolumn{3}{|c|}{ RFS } & \multicolumn{3}{|c|}{ OS } \\
\hline & & Hazard ratio & $95 \% \mathrm{Cl}$ & $P$ & Hazard ratio & $95 \% \mathrm{Cl}$ & $P$ \\
\hline $\mathrm{nSUV}_{\text {peak }}$ of primary tumor & 120 & 0.932 & $0.837-1.038$ & 0.202 & 0.984 & $0.860-1.127$ & 0.820 \\
\hline nSUV $_{\text {peak }}$ of hepatic metastasis & 120 & 1.106 & $0.982-1.245$ & 0.097 & 1.209 & $1.055-1.386$ & 0.006 \\
\hline $\mathrm{M} / \mathrm{P}$ ratio of $\mathrm{nSUV}_{\text {peak }}$ & 120 & 2.351 & $1.308-4.226$ & 0.004 & 1.849 & $0.891-3.837$ & 0.099 \\
\hline MTV of primary tumor $\left(\mathrm{cm}^{3}\right)$ & 120 & 1.012 & $0.996-1.028$ & 0.139 & 1.005 & $0.988-1.021$ & 0.589 \\
\hline MTV of hepatic metastasis $\left(\mathrm{cm}^{3}\right)$ & 120 & 1.003 & $1.000-1.006$ & 0.068 & 1.003 & $1.000-1.006$ & 0.058 \\
\hline $\mathrm{M} / \mathrm{P}$ ratio of $\mathrm{MTV}$ & 120 & 1.036 & $0.983-1.092$ & 0.184 & 1.051 & $0.989-1.117$ & 0.108 \\
\hline $\mathrm{nTLG}$ of primary tumor $\left(\mathrm{cm}^{3}\right)$ & 120 & 1.001 & $0.997-1.005$ & 0.702 & 1.000 & $0.996-1.004$ & 0.949 \\
\hline nTLG of hepatic metastasis $\left(\mathrm{cm}^{3}\right)$ & 120 & 1.001 & $1.000-1.002$ & 0.065 & 1.001 & $1.000-1.002$ & 0.023 \\
\hline $\mathrm{M} / \mathrm{P}$ ratio of $\mathrm{nTLG}$ & 120 & 1.040 & $0.989-1.093$ & 0.129 & 1.049 & $0.989-1.112$ & 0.108 \\
\hline
\end{tabular}

where sex was male $=1$, female $=0 ; \mathrm{MPR}_{\mathrm{SUV}}, \mathrm{M} / \mathrm{P}$ ratio of $\mathrm{SUV}_{\text {peak }} ; \mathrm{S}_{\mathrm{H}}$, size of hepatic metastasis $(\mathrm{cm}) ; \mathrm{N}_{\mathrm{H}}$, number of hepatic metastasis; $\mathrm{A}$, age (y); $\mathrm{SUV}_{\mathrm{P}}, \mathrm{nSUV}_{\text {peak }}$ of primary tumor; $\mathrm{SUV}_{\mathrm{H}}, \mathrm{nSUV}_{\text {peak }}$ of hepatic metastasis; and DG, poorly differentiated $=1$, well or moderately differentiated $=0$.

The mean $\pm \mathrm{SD}$ values of $\mathrm{PS}_{\mathrm{RFS}}$ and $\mathrm{PS}_{\mathrm{OS}}$ were $1.425 \pm 0.495$ (range, 0.437-3.090) and $2.634 \pm 0.723$ (range, 0.965-4.633), respectively. Univariate Cox regression analysis showed that 1unit increases of $\mathrm{PS}_{\mathrm{RFS}}$ and $\mathrm{PS}_{\mathrm{OS}}$ are associated with a 2.73-fold increase in the risk of tumor recurrence (hazard ratio, 2.73; $95 \%$ CI, 1.67-4.46, $P<0.001)$ and with a 2.73 -fold increase in the risk of death (hazard ratio, 2.73 ; 95\% CI, 1.78-4.17, $P<0.001$ ), respectively. $\mathrm{PS}_{\mathrm{RFS}}$ and $\mathrm{PS}_{\mathrm{OS}}$ remained significant $(P<0.001)$ after adjusting for the Fong's score (Supplemental Table 3).

Kaplan-Meier survival curves were plotted for the optimal cutoff values of $\mathrm{PS}_{\mathrm{RFS}}$ (Fig. 2A) and $\mathrm{PS}_{\mathrm{OS}}$ (Fig. 2B). The survival differences between the dichotomized groups were statistically significant $\left(P=0.0018\right.$ for $\mathrm{PS}_{\mathrm{RFS}} ; P<0.0001$ for $\left.\mathrm{PS}_{\mathrm{OS}}\right)$.

\section{DISCUSSION}

The most important contribution of this study is the evaluation of the prognostic significance of a complete set of metabolic parameters (SUV, MTV, and TLG) for both primary colorectal tumors and hepatic metastases in an important clinical settingthat is, curative-intent simultaneous colorectal and hepatic surgery for the treatment of SCLM. Several previous studies have investigated whether there is any prognostic role of ${ }^{18} \mathrm{~F}-\mathrm{FDG} \mathrm{PET} / \mathrm{CT}$ in cases of hepatic metastasis from a primary CRC. A study by De Geus-Oei et al. reported that a high SUV of hepatic metastases is significantly associated with poor survival, although the study included both patients who underwent surgery and patients who received chemotherapy (15). Riedl et al. demonstrated that the $\mathrm{SUV}_{\text {max }}$ of hepatic metastases is associated with tissue markers of poor prognosis (glucose transporter $1, \mathrm{Ki}-67$, and p53) and prognosis itself, but there was no mention of whether the liver metastases were synchronous or metachronous and whether the $\mathrm{SUV}_{\max }$ was for the primary tumor or the hepatic metastasis (16). Recently, Muralidharan et al. have reported that the MTV and TLG, but not $\mathrm{SUV}_{\max }$, of a hepatic metastasis is significantly associated with prognosis. However, the study included a relatively limited number of patients $(n=$ 30 ), and there was no mention of whether the liver metastases analyzed were synchronous or metachronous. Moreover, it included only patients who underwent neoadjuvant chemotherapy.

In the current study, we show that the $\mathrm{SUV}_{\text {peak }}$ of the primary tumor and hepatic metastasis possesses independent prognostic

TABLE 5

Multivariate Cox Regression Models for RFS

\begin{tabular}{|c|c|c|c|c|c|}
\hline Model & Variable & $\beta$ & Hazard ratio & $95 \% \mathrm{Cl}$ & $P$ \\
\hline \multirow[t]{5}{*}{1} & Sex (male) & 0.491 & 1.634 & $0.979-2.726$ & 0.060 \\
\hline & $\mathrm{nSUV}_{\text {peak }}$ of primary tumor & -0.136 & 0.872 & $0.763-0.998$ & 0.047 \\
\hline & nSUV $_{\text {peak }}$ of hepatic metastasis & 0.218 & 1.244 & $1.002-1.543$ & 0.048 \\
\hline & Size of hepatic metastasis $(\mathrm{cm})$ & 0.050 & 1.051 & $0.937-1.180$ & 0.393 \\
\hline & No. of hepatic metastasis & 0.169 & 1.184 & $0.994-1.410$ & 0.058 \\
\hline \multirow[t]{4}{*}{2} & Sex (male) & 0.508 & 1.663 & $0.997-2.774$ & 0.051 \\
\hline & $\mathrm{M} / \mathrm{P}$ ratio of $\mathrm{SUV}_{\text {peak }}$ & 0.735 & 2.086 & $1.041-4.180$ & 0.038 \\
\hline & Size of hepatic metastasis $(\mathrm{cm})$ & 0.070 & 1.073 & $0.967-1.190$ & 0.183 \\
\hline & No. of hepatic metastasis & 0.185 & 1.204 & $1.011-1.433$ & 0.037 \\
\hline \multirow[t]{4}{*}{3} & Sex (male) & 0.492 & 1.635 & $0.979-2.730$ & 0.060 \\
\hline & MTV of hepatic metastasis $\left(\mathrm{cm}^{3}\right)$ & 0.000 & 1.000 & $0.994-1.005$ & 0.887 \\
\hline & Size of hepatic metastasis $(\mathrm{cm})$ & 0.127 & 1.136 & $0.964-1.338$ & 0.129 \\
\hline & No. of hepatic metastasis & 0.213 & 1.237 & $1.040-1.472$ & 0.016 \\
\hline \multirow[t]{4}{*}{4} & Sex (male) & 0.490 & 1.633 & $0.978-2.726$ & 0.061 \\
\hline & nTLG of hepatic metastasis $\left(\mathrm{cm}^{3}\right)$ & 0.000 & 1.000 & $0.998-1.002$ & 0.937 \\
\hline & Size of hepatic metastasis $(\mathrm{cm})$ & 0.123 & 1.131 & $0.955-1.338$ & 0.153 \\
\hline & No. of hepatic metastasis & 0.212 & 1.237 & $1.039-1.472$ & 0.017 \\
\hline
\end{tabular}


TABLE 6

Multivariate Cox Regression Models for OS

\begin{tabular}{|c|c|c|c|c|c|}
\hline Model & Variable & $\beta$ & Hazard ratio & $95 \% \mathrm{Cl}$ & $P$ \\
\hline \multirow[t]{5}{*}{5} & Age $(y)$ & 0.035 & 1.036 & $1.001-1.073$ & 0.047 \\
\hline & $\mathrm{nSUV}_{\text {peak }}$ of primary tumor & -0.152 & 0.859 & $0.717-1.030$ & 0.101 \\
\hline & nSUV $_{\text {peak }}$ of hepatic metastasis & 0.363 & 1.438 & $1.080-1.916$ & 0.013 \\
\hline & Size of hepatic metastasis $(\mathrm{cm})$ & 0.032 & 1.033 & $0.895-1.191$ & 0.660 \\
\hline & Differentiation grade (poor) & 1.344 & 3.836 & $1.255-11.724$ & 0.018 \\
\hline \multirow[t]{4}{*}{6} & Age $(y)$ & 0.032 & 1.032 & $0.997-1.069$ & 0.070 \\
\hline & $\mathrm{M} / \mathrm{P}$ ratio of $\mathrm{SUV}_{\text {peak }}$ & 0.233 & 1.263 & $0.497-3.207$ & 0.624 \\
\hline & Size of hepatic metastasis $(\mathrm{cm})$ & 0.112 & 1.118 & $0.986-1.269$ & 0.082 \\
\hline & Differentiation grade (poor) & 1.546 & 4.694 & $1.515-14.515$ & 0.007 \\
\hline \multirow[t]{4}{*}{7} & Age $(y)$ & 0.031 & 1.031 & $0.997-1.067$ & 0.077 \\
\hline & MTV of hepatic metastasis $\left(\mathrm{cm}^{3}\right)$ & 0.000 & 1.000 & $0.993-1.007$ & 0.914 \\
\hline & Size of hepatic metastasis $(\mathrm{cm})$ & 0.138 & 1.148 & $0.915-1.440$ & 0.234 \\
\hline & Differentiation grade (poor) & 1.635 & 5.127 & $1.756-14.975$ & 0.003 \\
\hline \multirow[t]{4}{*}{8} & Age $(y)$ & 0.031 & 1.031 & $0.997-1.067$ & 0.077 \\
\hline & $\mathrm{nTLG}$ of hepatic metastasis $\left(\mathrm{cm}^{3}\right)$ & 0.001 & 1.001 & $0.998-1.003$ & 0.643 \\
\hline & Size of hepatic metastasis $(\mathrm{cm})$ & 0.078 & 1.081 & $0.854-1.368$ & 0.516 \\
\hline & Differentiation grade (poor) & 1.651 & 5.214 & $1.783-15.248$ & 0.003 \\
\hline
\end{tabular}

significance, even after adjusting for other clinicopathologic prognostic variables. In contrast, volumetric parameters (MTV and TLG) did not remain significant after adjusting for the size of the hepatic metastases, suggesting that the prognostic performances of MTV and TLG can be attributed to their abilities to act as surrogate measures of the sizes of hepatic metastases. This notion is supported by the fact that, in our present data, the cubic root of the MTV of the largest hepatic metastasis was highly correlated with its size ( $r=0.929, P<0.0001$; Supplemental Fig. 1A). The situation is similar for the TLG. Although the TLG is a composite variable derived from $\mathrm{SUV}_{\text {mean }}$ and MTV, a major proportion of the variation in TLG values can be attributed to variation in the MTV, and the contribution of SUV $_{\text {mean }}$ to the variation of TLG is relatively small. Our data indicate that the coefficient of variation (i.e., SD divided by the mean) of the $\mathrm{SUV}_{\text {mean }}$ was 0.49 , whereas that of MTV was 2.14, indicating that MTV is 4 times more variable than $\mathrm{SUV}_{\text {mean }}$. Hence, the variation in the TLG tends to closely follow the variation in the MTV. For this reason, the cubic root of the TLG of the largest hepatic metastasis was also highly correlated with its size $(r=0.928, P<0.0001$; Supplemental Fig. $1 \mathrm{~B})$, as in the case of the MTV. This issue was not addressed in the work of Muralidharan et al. (17).

The above arguments we have put forward regarding MTV and TLG are not an assertion that these measures have no prognostic usefulness. In the case of hepatic metastasis, most of the tumors are nearly spheric in shape. Hence, the cubic root of the tumor volume (e.g., MTV and CT volume) tends to be highly correlated with the single-dimensional tumor size. However, in the case of irregularly shaped tumors (such as those of head and neck cancers) of which the patterns of spread are shaped by the complex anatomy of multiple fascial planes, the cubic root of the tumor volume is expected to be less correlated with the largest singledimensional tumor size than for spheric tumors. In this case, MTV would not be a mere surrogate of the tumor size. This speculation may partly explain why MTV has proved its prognostic usefulness in several studies that have involved head and neck cancers (2022).

Our results also consistently demonstrate that clinicopathologic and metabolic parameters of hepatic metastases are prognostically more important than those of the primary tumors. Most of the variables that pertain to the primary tumor were prognostically not significant for the patient cohort included in the current study. Primary colorectal tumor parameters are expected to be associated with prognosis in cases of locoregional disease. However, it seems that once a liver metastasis develops, the prognosis becomes primarily dependent on the parameters associated with this hepatic metastasis and not on the characteristics of the primary tumor. One possible explanation would be that parameters for the hepatic metastasis might represent the duration or proliferative rate of the hepatic metastatic growth, which is associated with the development of hidden metastasis. If this is true, a large tumor burden or increased metabolic activity of known hepatic metastases would be associated with an increased likelihood of a subclinical distant metastasis.

An interesting result from the current study is the nature of the relationship between the $\mathrm{SUV}_{\text {peak }}$ of primary colorectal tumors and that of hepatic metastases in predicting RFS (Table 5, model 1). These 2 variables were not significant by univariate analysis, although they became statistically significant in the multivariate analysis. Whereas a high $\mathrm{SUV}_{\text {peak }}$ of hepatic metastases was found to be associated with a poor prognosis, a high $\mathrm{SUV}_{\text {peak }}$ of primary tumors was associated with a good prognosis, despite the fact that these 2 parameters are positively correlated (Supplemental Table 1). These results partly explain why each of these parameters was not significant in the univariate analysis - that is, opposing prognostic effects might have caused each to cancel the effects of the other. It remains to be established why high $S_{U V}$ peak of primary tumors indicate a good prognosis, but one of the possible mechanisms would be the inhibition of the hepatic metastasis by the primary tumor. Peeters et al. have reported that the resection of primary tumors in patients with SCLM resulted in metabolic flare of hepatic metastasis, as visualized by ${ }^{18}$ F-FDG PET (23). The same authors also reported that the resection of the primary tumor is associated with decreased apoptosis and increased proliferation of the hepatic metastasis and showed that this result was associated with endogenous antiangiogenic substances (angiostatin and endostatin) in urine and plasma, which is thought to result from the secretion of these substances from the primary colorectal 


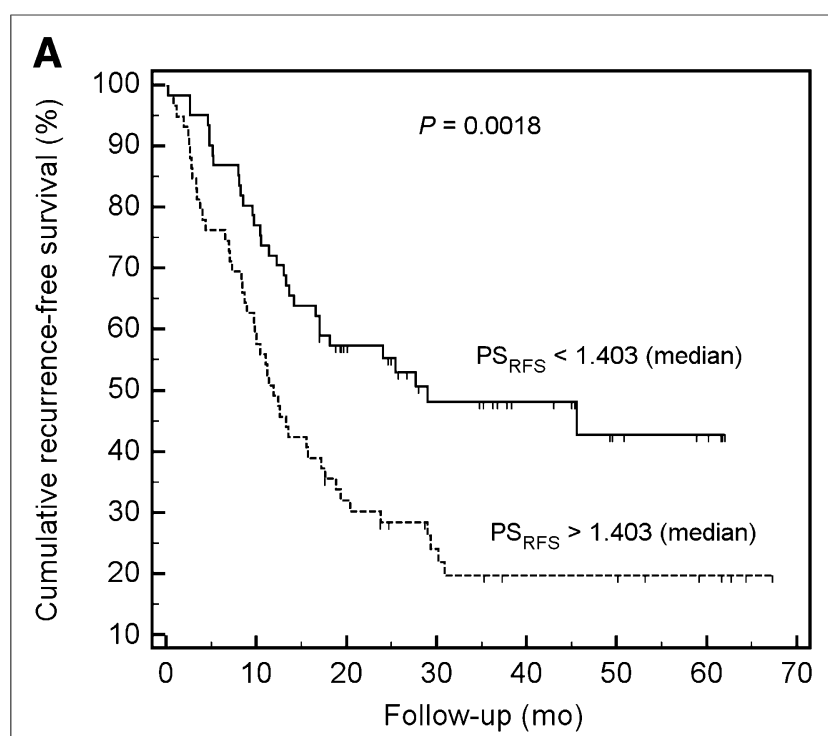

B

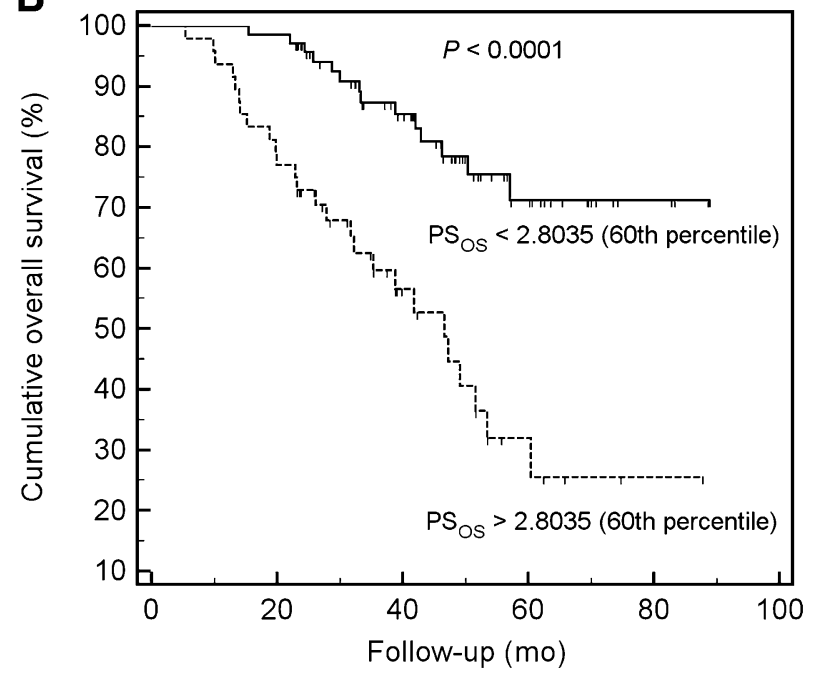

FIGURE 2. Kaplan-Meier curves for RFS dichotomized using median cutoff value of $\mathrm{PS}_{\mathrm{RFS}}(\mathrm{A})$ and for OS dichotomized using 60th-percentile cutoff value of $\mathrm{PS}_{\mathrm{OS}}(\mathrm{B})$.

tumor (24). These antiangiogenic substances could render the metastatic cells dormant (25). Therefore, it is tempting to speculate that increased metabolic activity of the primary tumor might be associated with increased inhibitory actions through the antiangiogenic molecules, which renders hepatic metastatic cells dormant. This speculation might also explain why the $S_{U V}$ peak of primary tumors was not found to be significant for the OS (antiangiogenic substances do not kill metastatic cells; they inhibit only metastases and render them dormant). Further studies will be needed to elucidate whether this possibility is correct.

There are limitations to this study. First, its retrospective nature potentially introduces the risk of selection bias. However, the relatively large number of our subjects $(n=120)$ and well-defined inclusion criteria may have mitigated this problem. Second, we included cases in which ${ }^{18} \mathrm{~F}$-FDG PET/CT was undertaken using 3 different scanners. To address this problem, we used $S_{U V} V_{\text {peak }}$ instead of $\mathrm{SUV}_{\text {max }}$ and normalized it with liver $\mathrm{SUV}_{\text {mean }}$. The normalization by liver $S_{U V} V_{\text {mean }}$ became necessary after the average tumor $\mathrm{SUV}_{\text {peak }}$ and liver $\mathrm{SUV}_{\text {mean }}$ turned out to differ significantly among the scanners. These interscanner differences disappeared after normalization (Supplemental Table 2). Through these modifications of the SUV, we contend that our main conclusions are not hampered by the multiple-scanner issue, although there may be minor deviations of coefficient figures in the presented prognostic models when compared with the suppositional model that would be derived from single-scanner data. Finally, our proposed prognostic models and scoring systems were not validated in an independent patient group. Prospective validation in an independent population would be required for their widespread clinical use.

\section{CONCLUSION}

In patients with SCLM who undergo curative-intent colorectal and liver surgery, PET metabolic parameters associated with hepatic metastasis have significant prognostic potential, whereas those associated with the primary colorectal tumor do not. The $\mathrm{SUV}_{\text {peak }}$ of hepatic metastasis possesses prognostic significance independent of other clinicopathologic variables, whereas volumetric PET parameters (such as MTV and TLG) are surrogate measures of tumor size. Higher $\mathrm{SUV}_{\text {peak }}$ for the hepatic metastases and lower $S_{U V}$ peak for the primary tumors are associated with shorter RFS. Further studies are needed to elucidate the underlying mechanism.

\section{DISCLOSURE}

The costs of publication of this article were defrayed in part by the payment of page charges. Therefore, and solely to indicate fact, this article is hereby marked "advertisement" in accordance with 18 USC section 1734 . No potential conflict of interest relevant to this article was reported.

\section{REFERENCES}

1. Stangl R, Altendorf-Hofmann A, Charnley RM, Scheele J. Factors influencing the natural history of colorectal liver metastases. Lancet. 1994;343:1405-1410.

2. Scheele J, Stangl R, Altendorf-Hofmann A. Hepatic metastases from colorectal carcinoma: impact of surgical resection on the natural history. $\mathrm{Br} J$ Surg. 1990;77:1241-1246.

3. Sugarbaker PH. Surgical decision making for large bowel cancer metastatic to the liver. Radiology. 1990;174:621-626.

4. Kanas GP, Taylor A, Primrose JN, et al. Survival after liver resection in metastatic colorectal cancer: review and meta-analysis of prognostic factors. Clin Epidemiol. 2012;4:283-301.

5. Sugihara K, Hojo K, Moriya Y, Yamasaki S, Kosuge T, Takayama T. Pattern of recurrence after hepatic resection for colorectal metastases. Br J Surg. 1993;80:10321035 .

6. Scheele J, Stang R, Altendorf-Hofmann A, Paul M. Resection of colorectal liver metastases. World J Surg. 1995;19:59-71.

7. Tsai MS, Su YH, Ho MC, et al. Clinicopathological features and prognosis in resectable synchronous and metachronous colorectal liver metastasis. Ann Surg Oncol. 2007;14:786-794.

8. Fong Y, Fortner J, Sun RL, Brennan MF, Blumgart LH. Clinical score for predicting recurrence after hepatic resection for metastatic colorectal cancer: analysis of 1001 consecutive cases. Ann Surg. 1999;230:309-318, discussion 318-321.

9. Iwatsuki S, Dvorchik I, Madariaga JR, et al. Hepatic resection for metastatic colorectal adenocarcinoma: a proposal of a prognostic scoring system. J Am Coll Surg. 1999;189:291-299.

10. Rees M, Tekkis PP, Welsh FK, O'Rourke T, John TG. Evaluation of long-term survival after hepatic resection for metastatic colorectal cancer: a multifactorial model of 929 patients. Ann Surg. 2008;247:125-135.

11. Gregoire E, Hoti E, Gorden DL, de la Serna S, Pascal G, Azoulay D. Utility or futility of prognostic scoring systems for colorectal liver metastases in an era of advanced multimodal therapy. Eur J Surg Oncol. 2010;36:568-574.

12. Pawlik TM, Choti MA. Shifting from clinical to biologic indicators of prognosis after resection of hepatic colorectal metastases. Curr Oncol Rep. 2007;9:193-201. 
13. Yoo S, Kim J, Chong A, et al. Metabolic tumor volume measured by F-18 FDG PET/CT can further stratify the prognosis of patients with stage IV non-small cell lung cancer. Nucl Med Mol Imaging. 2012;46:286-293.

14. Vansteenkiste JF, Stroobants SG, Dupont PJ, et al. Prognostic importance of the standardized uptake value on ${ }^{18} \mathrm{~F}$-fluoro-2-deoxy-glucose-positron emission tomography scan in non-small-cell lung cancer: an analysis of 125 cases. Leuven Lung Cancer Group. J Clin Oncol. 1999;17:3201-3206.

15. de Geus-Oei LF, Wiering B, Krabbe PF, Ruers TJ, Punt CJ, Oyen WJ. FDG-PET for prediction of survival of patients with metastatic colorectal carcinoma. Ann Oncol. 2006;17:1650-1655.

16. Riedl CC, Akhurst T, Larson S, et al. ${ }^{18}$ F-FDG PET scanning correlates with tissue markers of poor prognosis and predicts mortality for patients after liver resection for colorectal metastases. J Nucl Med. 2007;48:771-775.

17. Muralidharan V, Kwok M, Lee ST, Lau L, Scott AM, Christophi C. Prognostic ability of ${ }^{18} \mathrm{~F}-\mathrm{FDG}$ PET/CT in the assessment of colorectal liver metastases. J Nucl Med. 2012;53:1345-1351.

18. Soret M, Bacharach SL, Buvat I. Partial-volume effect in PET tumor imaging. J Nucl Med. 2007;48:932-945.

19. Lodge MA, Chaudhry MA, Wahl RL. Noise considerations for PET quantification using maximum and peak standardized uptake value. J Nucl Med. 2012; 53:1041-1047.
20. Chung MK, Jeong HS, Park SG, et al. Metabolic tumor volume of $\left[{ }^{18} \mathrm{~F}\right]-$ fluorodeoxyglucose positron emission tomography/computed tomography predicts short-term outcome to radiotherapy with or without chemotherapy in pharyngeal cancer. Clin Cancer Res. 2009;15:5861-5868.

21. La TH, Filion EJ, Turnbull BB, et al. Metabolic tumor volume predicts for recurrence and death in head-and-neck cancer. Int J Radiat Oncol Biol Phys. 2009;74:1335-1341.

22. Murphy JD, La TH, Chu K, et al. Postradiation metabolic tumor volume predicts outcome in head-and-neck cancer. Int J Radiat Oncol Biol Phys. 2011;80:514521.

23. Peeters CF, de Geus LF, Westphal JR, et al. Decrease in circulating anti-angiogenic factors (angiostatin and endostatin) after surgical removal of primary colorectal carcinoma coincides with increased metabolic activity of liver metastases. Surgery. 2005; $137: 246-249$.

24. Peeters CF, de Waal RM, Wobbes T, Westphal JR, Ruers TJ. Outgrowth of human liver metastases after resection of the primary colorectal tumor: a shift in the balance between apoptosis and proliferation. Int J Cancer. 2006;119:12491253.

25. Peeters CF, de Waal RM, Wobbes T, Ruers TJ. Metastatic dormancy imposed by the primary tumor: does it exist in humans? Ann Surg Oncol. 2008;15:33083315 . 